\title{
The titanium-made growth-guidance technique for early-onset scoliosis at minimum 2-year follow-up: A prospective multicenter study
}

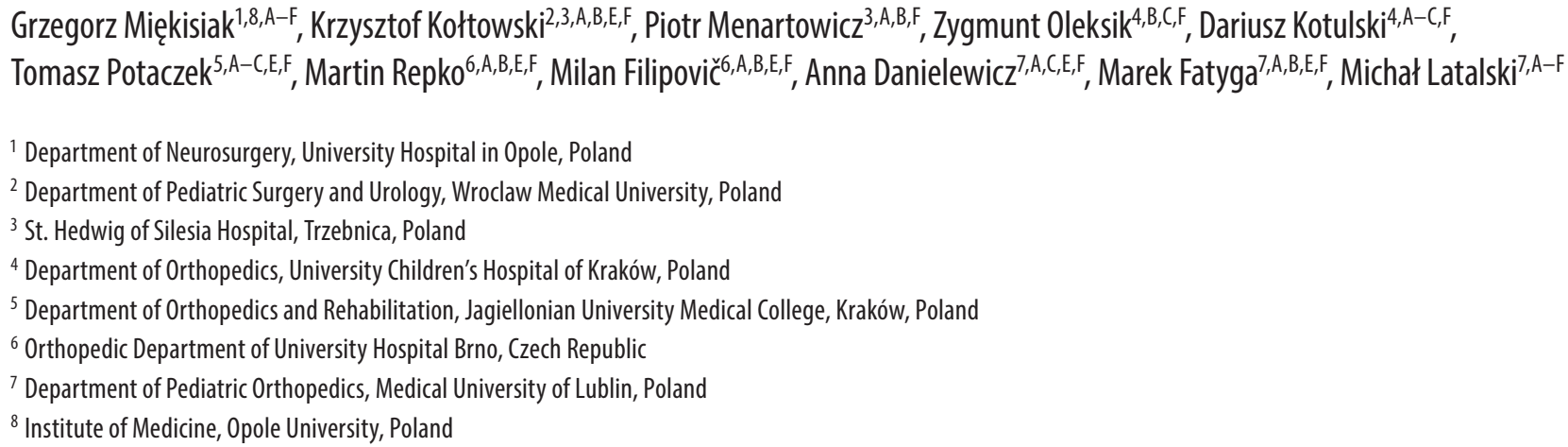

Address for correspondence

Grzegorz Miękisiak

E-mail: gmiekisiak@gmail.com

Funding sources

None declared

Conflict of interest

None declared

Acknowledgements

The authors would like to thank Ms. Ewelina Brunicka for her commitment in all stages of the study.

Received on October 2, 2018

Reviewed on October 16, 2018

Accepted on December 21, 2018

Published online on June 18, 2019

Cite as

Miękisiak G, Kołtowski K, Menartowicz P, et al. The titaniummade growth-guidance technique for early-onset scoliosis at minimum 2-year follow-up: A prospective multicenter study. Adv Clin Exp Med. 2019;28(8):1073-1077.

doi:10.17219/acem/102269

DOI

10.17219/acem/102269

Copyright

Copyright by Author(s)

This is an article distributed under the terms of the

Creative Commons Attribution Non-Commercial License

(http://creativecommons.org/licenses/by-nc-nd/4.0/)

\begin{abstract}
Background. The management of early-onset scoliosis (EOS) remains a serious challenge in pediatric orthopedics. The growth-guidance system (GGS) is a surgical option that allows continuous growth along a rod, averting the need for repeated operative lengthening.

Objectives. The objective of this study was to evaluate the outcomes of the GGS in the treatment of EOS.

Material and methods. A prospective study, including 81 patients from 4 departments treated with this method from 2013 to 2015, was conducted with a minimum follow-up period of 24 months. The follow-up data of 57 patients was available, thus the drop-out rate was $29.63 \%$. There were 44 girls with a mean age of 10.03 years and 13 boys with a mean age of 8.04 years.
\end{abstract}

Results. The mean preoperative Cobb angle was $65.3^{\circ}\left(\right.$ range $\left.36^{\circ}-139^{\circ}\right)$ was corrected to $23.7^{\circ}\left(2^{\circ}-94^{\circ}\right)$, and at the end of the 2 -year follow-up increased to $30.7^{\circ}\left(8^{\circ}-93^{\circ}\right)$. The predominant proximal level of instrumentation was $\mathrm{T} 5$ and the distal was $\mathrm{L} 1$. The combined length of $\mathrm{T1}-\mathrm{T} 12$ and $\mathrm{T} 12-\mathrm{S1}$ increased on average by $33.19 \mathrm{~mm}$ in 24 months. The overall rate of serious complications was 43.86\%. The most prevalent device-related complications were: the dislodgement of top screws because of the short length of the rod (14 cases), the implant failure (11 cases) and loss of correction (9 cases).

Conclusions. The results show that the GGS used in this study allows for a good and stable correction while preserving the ability of the spine to grow in at least a 2-year follow-up. The complication rate is acceptable and comparable with other growth-friendly techniques. To date, this is the largest successful study on the use of titanium-made GGSs.

Key words: early-onset scoliosis, scoliosis, spine, titanium 


\section{Introduction}

Early-onset scoliosis (EOS) is a very serious, potentially life-threatening clinical condition, ${ }^{1}$ which develops in young children under the age of 10 . Patients with progressive thoracic scoliosis tend to develop, as a part of natural history, restrictive lung disease and possibly cardiac disease associated with early mortality. ${ }^{1-3}$

Despite progress in the field of spinal disorders, managing EOS remains a serious challenge. The first line of treatment consisting of conservative methods, such as bracing and casting, is often unsuccessful and is often used to buy time for skeletal maturity. ${ }^{4}$ Early attempts to utilize a classical fusion technique, according to the belief that a short and straight spine was superior to a long and deformed one, failed miserably. ${ }^{5}$ Studies have reported that early fusion leads to pulmonary compromise and poor overall quality of life, ${ }^{6,7}$ as it is crucial to allow for accommodation of developing lungs. Campbell et al. ${ }^{8}$ defined the term "thoracic insufficiency syndrome" as the inability of the thorax to allow effective respiration and growth of lungs. One of the most appealing concepts of surgical treatment, besides distraction-based methods, is the growth-guidance system (GGS), which was first introduced as the Luque trolley, ${ }^{9}$ and further improved into the Shilla method. ${ }^{10}$ This technique uses stainless steel rods and specially modified locking nuts that allow for fairly unrestricted sliding motion. Early results have shown good results with an acceptable complication rate. ${ }^{11}$ The system described in the present study is based on a similar principle, though it is made of titanium. The purpose of this study was to analyze the results and complications in a group of patients with a minimum 24-months follow-up.

\section{Material and methods}

An approval No. DS240/2013 was obtained from the ethics committee of the Medical University of Lublin, Poland. In a prospective uncontrolled multicenter study, 81 EOS patients from 4 departments of 2 countries (Poland and Czech Republic) were enrolled. They underwent index surgery from 2013 to 2015. The 24-months follow-up data was available for 57 patients and they were included in this study. Thus, the overall follow-up rate was $70.37 \%$. The demographics and basic characteristics are shown in Table 1. There were 44 girls and 13 boys; boys were significantly younger. The majority of the patients, $76.79 \%$, belonged to Risser 0 grade; the difference between the sexes was not statistically significant. The median proximal end of deformity was $\mathrm{T} 5$ in both the sexes; the median distal end was L1 and T12 for females and males, respectively. The majority of the patients (76.09\%) had single curve deformities, $80 \%$ in females and $63.64 \%$ in males; the difference between the sexes was statistically insignificant. Eighteen patients were syndromic. In all but 7 cases surgical treatment was preceded by unsuccessful conservative treatment (rehabilitation and bracing).
Table 1. Demographics and basic characteristics

\begin{tabular}{|l|c|c|}
\multicolumn{1}{|c|}{ Variables } & Female & Male \\
\hline Number of patients & 44 & 13 \\
\hline $\begin{array}{l}\text { Age at index surgery } \pm \text { SD } \\
\begin{array}{l}\text { Percentage of Risser 0 patients } \\
\text { (the rest Risser 1) }\end{array}\end{array}$ & $10.03 \pm 4.82^{*}$ & $8.04 \pm 3.65^{*}$ \\
\hline $\begin{array}{l}\text { Predominant proximal end level } \\
\text { of scoliosis }\end{array}$ & T5 & 61.54 \\
\hline $\begin{array}{l}\text { Predominant distal end level } \\
\text { of scoliosis }\end{array}$ & L1 & T5 \\
\hline $\begin{array}{l}\text { Percentage of patients with a single } \\
\text { curve }\end{array}$ & 12 (9-16) & 11 (10-16) \\
\hline $\begin{array}{l}\text { Median number of instrumented } \\
\text { levels (range) }\end{array}$ & & 63.64 \\
\hline
\end{tabular}

${ }^{*} \mathrm{p}<0.05 ;$ SD - standard deviation.

\section{Surgery}

All the subjects underwent a 3-plane correction of scoliosis and instrumentation with Socore GGS (Novaspine, Salouël, France) pedicle screws. The spine was exposed in a standard subperiosteal fashion near the apex. In the apical zone, the rods were tightly fixed to screws using classical locking caps. A fusion-promoting environment was created to allow for 2-3 level spondylodesis. The goal was to make the apical level as neutral as possible. The transverse connector was used on a case-by-case basis. At both ends of the instrumentation, extraperiosteal dissection was used along with specially designed locking caps that enabled relatively unconstrained sliding movement of the rod inside the screw head (Fig. 1). The purpose was to convert the grow-friendly stabilization into rigid spondylodesis after some 2-3 years at the surgeon's discretion, when sufficient vertebral column growth has been achieved.

The patients did not use external stabilization such as bracing and/or casting. Radiographic analysis was

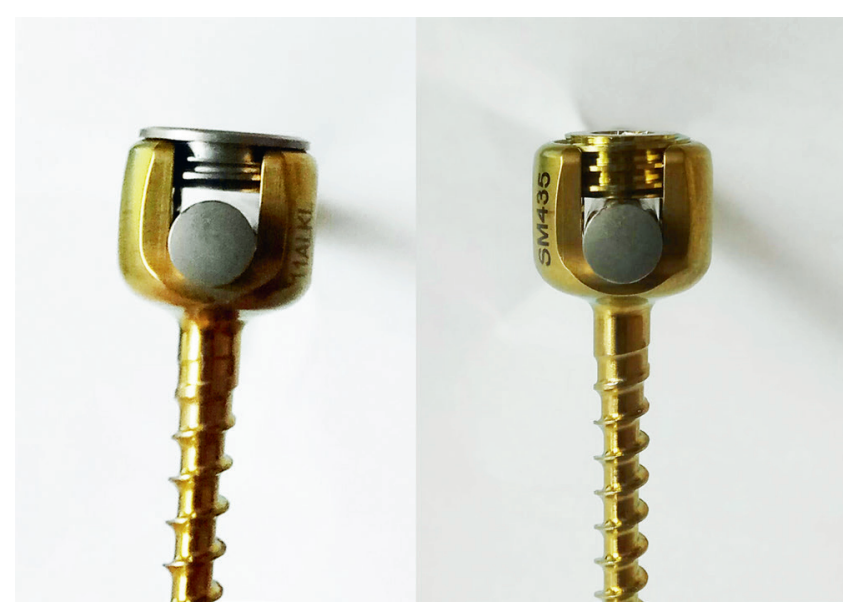

Fig. 1. Comparison of the sliding GGS screw cap (left) and a traditional locking cap (right) 
Table 2. Device-related complications according to the classification system by Smith et al. ${ }^{14}$

\begin{tabular}{|l|c|c|}
\hline Grade & Description & $\begin{array}{c}\text { Number } \\
\text { of cases }\end{array}$ \\
\hline I & Does not require unplanned surgery & 32 \\
\hline II & Requires unplanned surgery/surgeries & 17 \\
\hline III & Requires abandoning growth-friendly strategy & 8 \\
\hline IV & Death & 0 \\
\hline
\end{tabular}

performed with taking standard standing X-rays just before and soon after the surgery, and at the follow-up. Besides the Cobb angle, the apical vertebral rotation (AVR) was evaluated using the Nash and Moe method, ${ }^{12}$ which classifies the degree of rotation into one of the 5 groups $(0-I V)$. The differences in mean values of Cobb angle were compared using the paired Student's t-test, while median values of AVR were evaluated using the Wilcoxon test.

The changes in the lengths from the point located right between the pedicles of the T1 and T12 vertebrae as well as between T12 and S1 were calculated and evaluated using the paired Student's t-test. The implant-related complications were categorized according to the classification system described by Smith et al., ${ }^{13}$ which is shown in Table 2.

\section{Results}

As shown in Fig. 2, the average angle of the major curve was $65.3^{\circ} \pm 17.6^{\circ}$ before surgical treatment, $23.7^{\circ} \pm 15.77^{\circ} \mathrm{im}$ mediately after surgery and $30.7^{\circ} \pm 17.56^{\circ}$ after 24 months of surgery. The changes in measurement were statistically significant at $\mathrm{p}<0.01$. The T1-T12 and T12-S1 lengths increased at each time point: they measured $197.7 \pm 27.33 \mathrm{~mm}$ and $136.93 \pm 21.14 \mathrm{~mm}$ before the surgery, $218.7 \pm 27.39 \mathrm{~mm}$ and $149.53 \pm 21.74 \mathrm{~mm}$ immediately after surgery, and

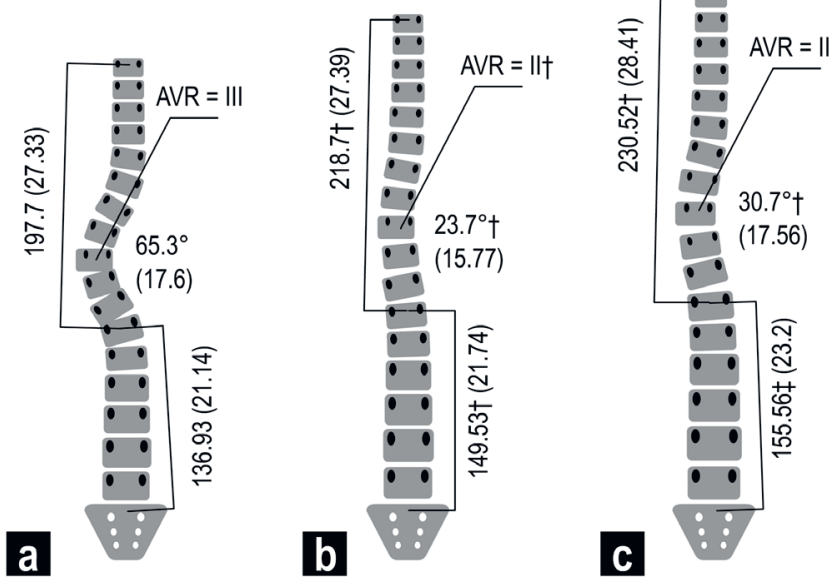

Fig. 2. Schematic diagram of the parameters before (a), soon after (b) and 2 years after (c) surgery

${ }^{*} p<0.0001 ;+p<0.01, S D-$ standard deviation (in parentheses).
$230.52 \pm 28.41 \mathrm{~mm}$ and $155.56 \pm 23.2 \mathrm{~mm} 24$ months after surgery, respectively. The differences were statistically significant at $\mathrm{p}<0.0001$.

The mean total length, measured by adding up both the lengths, was $325.11 \pm 61.62 \mathrm{~mm}$ before the surgery and increased by $26.38 \mathrm{~mm}$ on average after the surgery (351 $\pm 73.03 \mathrm{~mm})$. In the 2-year follow-up, it increased by further $33.19 \mathrm{~mm}$ to $384.66 \pm 42.03 \mathrm{~mm}$. The differences were statistically significant $(\mathrm{p}<0.0001)$ at every time point of measurement. The AVR decreased after the surgery from grade III to II $(\mathrm{p}<0.01)$. This value was maintained at the 24-month follow-up.

The dropout rate from the study was also analyzed. The mean age and the mean values for the largest Cobb angle of the study participants and drop-outs were 9.65 and 8.38 years, and $66.37^{\circ}$ and $60.43^{\circ}$, respectively. Both the differences were statistically insignificant.

A total of 57 device-related complications occurred (Table 2). The majority of the complications were minor, not requiring unplanned surgery. In 17 cases, unplanned surgeries were required, and in 8 cases, the growth-friendly technique had to be abandoned. Thus, the rate of serious complications was $43.86 \%$. The most prevalent device-related complication was associated with the length of the rod, which was too short, leading to the dislodgement of top screws (14 cases), followed by implant failure in 11 cases and loss of correction in 9 cases. All the complications are summarized in Table 3.

Table 3. Details of complications

\begin{tabular}{|l|c|}
\hline \multicolumn{1}{|c|}{ Description } & Number of cases \\
\hline Rod too short & 14 \\
\hline Implant failure/fracture & 11 \\
\hline Loss of correction & 10 \\
\hline Implant migration & 9 \\
\hline Infection & 3 \\
\hline Other & 10 \\
\hline Total & 57 \\
\hline
\end{tabular}

\section{Discussion}

Early-onset scoliosis is one of the most challenging problems in the field of spine surgery as the reasons are multi-faceted. The curves are often big and stiff; the patients frequently suffer from significant comorbidities, are underweight with poorly developed subcutaneous tissue, and are often osteopenic. ${ }^{14}$ Early trials with definite, single-stage fusion techniques failed, and the only reliable measure was repeated surgery. ${ }^{14}$ An obvious solution, considering the pathomechanism of EOS, would be to create a growth-friendly non-fusion method. , 15

Over the years, several different approaches have been attempted. Skaggs et al. ${ }^{16}$ divided the non-fusion surgical 


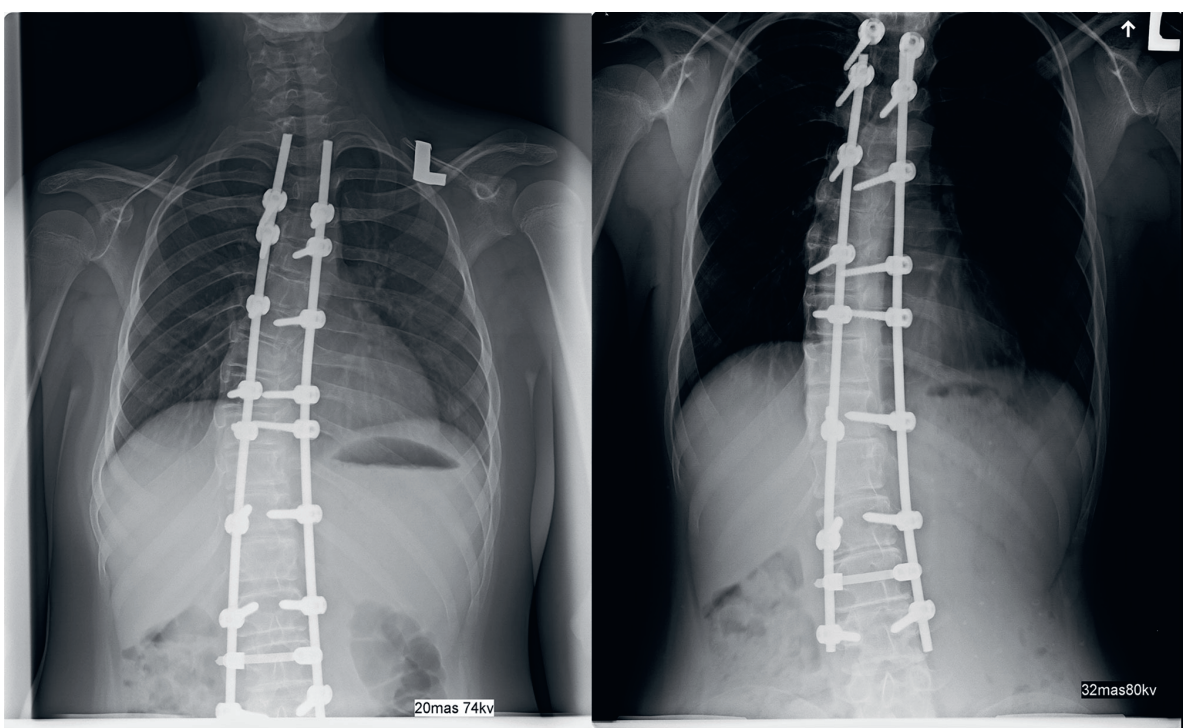

Fig. 3. The rod was too short for growth which occurred in 2 years after the index surgery (left to right)

techniques used in EOS into 3 groups: distraction-based systems, compression-based systems and GGSs. The latter is built around the idea of directing the growth of spine along rigid rods. The first GGS was the Luque trolley, introduced in 1977. ${ }^{17}$ The trolley comprised multiple sublaminar wires placed along rigid rods. The driving force was the spine itself, as it maintained its growth potential, despite the deformity. The results were generally unfavorable, ${ }^{15,18}$ and the main problem was premature fusion secondary to heterotopic ossification caused by periosteal stripping. ${ }^{11}$ As a result, the technique fell into disuse.

The Shilla system was introduced by McCarthy et al. ${ }^{19}$ It represents a major improvement over the trolley principle. The biggest advantage was the use of pedicle screws, instead of laminar wires, which allowed 3D manipulation of the curve. Furthermore, in theory, the lack of subperiosteal dissection for the placement of guide screws should limit the risk of premature fusion. Initial results were promising, and the authors were able to demonstrate the satisfactory growth of the trunk as well as good deformity correction, which was maintained after 2 years. ${ }^{11}$

The system described in the present study operates on the same principle as Shilla, the main difference being that titanium was used instead of stainless steel. This is particularly important in the case of sliding constructs as one of the major reported problems is metallosis, ${ }^{20}$ a deposition of metallic debris in the vicinity of the sliding rod. Although the significance of this phenomenon is yet to be studied, it has been associated with several side effects, such as implant failure, loosening and local tissue necrosis. ${ }^{21}$ Titanium metallosis is less studied, yet its toxicity requires extremely high circulating concentrations of the elements which are unlikely to occur from the degradation of an implant. ${ }^{22}$ In the present study, the deposition of metal debris was apparent in each and every re-operation (including final fusion) case. The significance of this phenomenon in the setting of GGS is yet to be evaluated. ${ }^{11}$
The first publication on the use of Socore GGS used in present study was published by Latalski et al. in $2013 .^{23}$ In the present study, we were able to demonstrate good correction in the coronal plane, with only modest loss, over the period studied. In the present study, the loss of correction was near $7^{\circ}$, similar to the study using the Shilla system. ${ }^{11}$ Ample derotation has been observed after initial surgery as AVR decreased from III to II, which was maintained over the 24-month period. To our knowledge, this is the first time this value has been reported for the guided growth technique.

The overall growth of T1-T12 + T12-S1 was $33.19 \mathrm{~mm}$. This value is within the same ballpark as the data from studies on the growth of a normal spine, where the annual increase is roughly $1 \mathrm{~cm}$ and $1.8 \mathrm{~cm} /$ year between age of 5 and 10, and age of 10 and skeletal maturity, respectively. ${ }^{24}$ As the majority of children in this study were around 10 years of age, the growth of the vertebral column seems almost unrestricted. Similar results were reported for magnetic MAGEC rods, with a comparable increase in the spinal growth; T1-S1 $6 \mathrm{~mm} /$ year in primary, and $12 \mathrm{~mm} /$ year in revision cases. ${ }^{25}$ In a similar article to this on Shilla system by McCarthy et al., ${ }^{11}$ instead of changes in absolute length, the relative growth of $13 \%$ was reported. It must be noted that in our case, instead of direct T1-S1 length, we used a combined length of T1-T12 and T12-S1; however, with the mean Cobb angle of $30.7^{\circ}$, this difference becomes irrelevant.

Our complication rate of $43.86 \%$ seems high for general standards of spinal surgery, but the EOS surgery is inevitably associated with high complication rates, even as high as $84 \%$, particularly in syndromic children. ${ }^{26}$ In a study comparing growth using magnetic rods and conventional rods, the overall complication rate was $76 \% .{ }^{27}$ On the other hand, 17 unplanned surgeries are far more acceptable than repeated lengthening surgeries required every 6 months. The most prevalent complication, i.e., the dislodgement of screws of rods that are too short, is a serious drawback 
(Fig. 3). The length of the rod is decided by the surgeon during surgery; too long rods may cause extensive skin and subcutaneous tissue irritation on the top of the construct, and damage to facet joins at the bottom.

This study has certain limitations. Long-term follow-ups until skeletal maturity is required. Although we assumed that all patients require a definite fusion by means of replacing the locking caps and spondylodesis, it is yet to be determined if this step is required in each case. Our study lacks data on the sagittal profile, in particular, on the upper T-spine kyphosis and proximal junctional kyphosis. Last but not the least, the presence of metallosis is yet to be studied.

\section{Conclusions}

To our knowledge, this is the largest study with a titanium-based GGS, and the interim results are encouraging. We were able to demonstrate good growth while maintaining the proper level of correction. Despite the limitations, we hope this study would contribute to the management of EOS, as not much work has been done using the modern GGSs.

\section{ORCID iDs}

Grzegorz Miękisiak (D) https://orcid.org/0000-0001-6781-7013 Tomasz Potaczek (D) https://orcid.org/0000-0001-9019-8644 Michał Latalski (D) https://orcid.org/0000-0002-7919-0294

\section{References}

1. Pehrsson K, Larsson S, Oden A, Nachemson A. Long-term followup of patients with untreated scoliosis: A study of mortality, causes of death, and symptoms. Spine (Phila Pa 1976). 1992;17(9):1091-1096.

2. Goldberg CJ, Gillic I, Connaughton O, et al. Respiratory function and cosmesis at maturity in infantile-onset scoliosis. Spine (Phila Pa 1976). 2003;28(20):2397-2406.

3. Fernandes $P$, Weinstein SL. Natural history of early onset scoliosis. J Bone Joint Surg Am. 2007;89(Suppl 1):21-33.

4. Hasler CC. Early-onset scoliosis: Contemporary decision-making and treatment options. J Pediatr Orthop. 2018;38(Suppl 1):S13-S20.

5. Tis JE, Karlin LI, Akbarnia BA, et al; Growing Spine Committee of the Scoliosis Research Society. Early onset scoliosis. J Pediatr Orthop. 2012;32(7):647-657.

6. Vitale MG, Matsumoto $H$, Bye MR, et al. A retrospective cohort study of pulmonary function, radiographic measures, and quality of life in children with congenital scoliosis: An evaluation of patient outcomes after early spinal fusion. Spine (Phila Pa 1976). 2008;33(11): 1242-1249.

7. Karol LA, Johnston C, Mladenov K, Schochet P, Walters P, Browne RH. Pulmonary function following early thoracic fusion in non-neuromuscular scoliosis. J Bone Joint Surg Am. 2008;90(6):1272-1281.
8. Campbell RM, Smith MD, Mayes TC, et al. The characteristics of thoracic insufficiency syndrome associated with fused ribs and congenital scoliosis. J Bone Joint Surg Am. 2003;85-A(3):399-408.

9. Luque ER. Paralytic scoliosis in growing children. Clin Orthop Relat Res. 1982;(163):202-209.

10. McCarthy RE, Sucato D, Turner JL, Zhang H, Henson MAW, McCarthy K. Shilla Growing rods in a caprine animal model: A pilot study. Clin Orthop Relat Res. 2010;468(3):705-710.

11. McCarthy RE, Luhmann S, Lenke L, McCullough FL. The Shilla growth guidance technique for early-onset spinal deformities at 2-year follow-up. J Pediatr Orthop. 2014;34(1):1-7.

12. Nash CL, Moe JH. A study of vertebral rotation. J Bone Joint Surg Am. 1969;51(2):223-229.

13. Smith JT, Johnston C, Skaggs D, Flynn J, Vitale M. A new classification system to report complications in growing spine surgery: A multicenter consensus study. J Pediatr Orthop. 2015;35(8):798-803

14. Fletcher ND, Bruce RW. Early onset scoliosis: Current concepts and controversies. Curr Rev Musculoskelet Med. 2012;5(2):102-110.

15. Mardjetko SM, Hammerberg KW, Lubicky JP, Fister JS. The Luque trolley revisited. Review of nine cases requiring revision. Spine (Phila Pa 1976). 1992;17(5):582-589.

16. Skaggs DL, Akbarnia BA, Flynn JM, Myung KS, Sponseller PD, Vitale MG; Chest Wall and Spine Deformity Study Group; Growing Spine Study Group; Pediatric Orthopaedic Society of North America; Scoliosis Research Society Growing Spine Study Committee. A classification of growth friendly spine implants. J Pediatr Orthop. 2014;34(3): 260-274.

17. Luque E, Cardoso A. Treatment of scoliosis without arthrodesis or external support: Preliminary report. Orthop Trans. 1977;119;276.

18. Pratt RK, Webb JK, Burwell RG, Cummings SL. Luque trolley and convex epiphysiodesis in the management of infantile and juvenile idiopathic scoliosis. Spine (Phila Pa 1976). 1999;24(15):1538-1547.

19. McCarthy RE, McCullough F, Luhmann SJ LL. Greater than two years follow-up Shilla growth enhancing system for the treatment of scoliosis in children. In: $2^{\text {nd }}$ Annual International Conference on Early Onset Scoliosis (ICEOS). Montreal, Canada; 2008.

20. Yang JH, Ham CH, Hwang YG, Suh SW. Metallosis: A complication in the guided growing rod system used in treatment of scoliosis. Indian J Orthop. 2017;51(6):714-718.

21. Neumann DRP, Thaler C, Hitzl W, Huber M, Hofstädter T, Dorn U. Longterm results of a contemporary metal-on-metal total hip arthroplasty: A 10-year follow-up study. J Arthroplasty. 2010;25(5):700-708.

22. Merritt K, Rodrigo JJ. Immune response to synthetic materials. Sensitization of patients receiving orthopaedic implants. Clin Orthop Relat Res. 1996;(326):71-79.

23. Latalski M, Fatyga M, Kołtowski K, Menartowicz P, Repko M, Filipovič M. Guided-growth implants in the treatment of early onset scoliosis. A pilot study. Ortop Traumatol Rehabil. 2013;15(1):23-29.

24. Dimeglio A, Canavese F. The growing spine: How spinal deformities influence normal spine and thoracic cage growth. Eur Spine J. 2012; 21(1):64-70.

25. Hickey BA, Towriss C, Baxter G, et al. Early experience of MAGEC magnetic growing rods in the treatment of early onset scoliosis. Eur Spine J. 2014;23(Suppl 1):S61-65.

26. Phillips JH, Knapp DR, Herrera-Soto J. Mortality and morbidity in early-onset scoliosis surgery. Spine (Phila Pa 1976). 2013;38(4):324-327.

27. Teoh $\mathrm{KH}$, Winson DMG, James $\mathrm{SH}$, et al. Do magnetic growing rods have lower complication rates compared with conventional growing rods? Spine J. 2016;16(Suppl 4):S40-S44. 